\title{
The couple business as a unique form of business: a review of the empirical evidence
}

\author{
Aliaa El Shoubaki ${ }^{1}$ (D) Jörn Block ${ }^{2} \cdot$ Frank Lasch $^{3}$ \\ Received: 15 May 2020 / Accepted: 4 November 2020 / Published online: 5 January 2021 \\ (c) Springer Nature Switzerland AG 2021
}

\begin{abstract}
Businesses run by romantic couples_couple businesses-are an important social and economic phenomenon. These businesses are widespread and represent a distinct form of business; they can be large corporations or home-based businesses, they can make large or small revenues, and the couples running them can have high or low levels of education. Scholars from different disciplines have addressed couple businesses, which makes the literature base fragmented. In this review of 71 articles on couple businesses, we synthesize the research around three guiding questions: what is a couple business (descriptions), where does it come from (antecedents), and where does it lead (outcomes)? Providing a cohesive picture of empirical research on couple businesses adds clarity and richness to the research field and increases our understanding of the phenomenon. Avenues for further research are discussed in five thematic areas: conceptualizations of couple businesses, work-home boundaries, gendered power differentials, and antecedents and outcomes of couple businesses.
\end{abstract}

Keywords Entrepreneurship $\cdot$ Couples $\cdot$ Life partners $\cdot$ Systematic review $\cdot$ Couple business $\cdot$ Family business

JEL Classification L26 · M10

Aliaa El Shoubaki

aliaa.shoubaki@vse.cz

Jörn Block

block@uni-trier.de

Frank Lasch

f.lasch@montpellier-bs.com

1 Prague University of Economics and Business, Nam. W. Churchilla 4, 13067 Praha 3, Czech Republic

2 Trier University, Universitätsring 15a, DM-Gebäude, Postfach 28, 54296 Trier, Germany

3 Montpellier Business School, 2300, Avenue des Moulins, 34080 Montpellier, France 


\section{Introduction}

The phenomenon of romantic couples working together has developed a new skin in the past decades (De Bruin et al. 2006; Marshack 1993). In preindustrial society, couples working together in their homes represent the core economic unit (Epstein 1971). The separation of economic production from the family household is a transformation that took place during the nineteenth century (Winch 1970). Previously confined to certain sectors such as farming and clergy (Fletcher 2010), joint work between couples is far more encompassing today. Currently, couples involved in business together may have a university education, establish their business as a corporation or a small entity, work from home or from an office, and earn millions or very little (Marshack 1993). This phenomenon evolved because of changes in the economic fabric since industrialization and its repercussions for families and individuals (Aldrich and Cliff 2003). In light of the current coronavirus crisis, we are witnessing one of these events that can change economic and social behaviors; i.e., many countries have been in a lockdown, imposing social distancing and temporary business shutdowns (e.g., businesses in the sectors of gastronomy, hospitality, airlines, and education; The Economist 2020). The longer the crisis persists, the deeper the changes are expected to sink into the organization of work, the appeal of certain sectors, and social and family dynamics. Thus, couples can become increasingly compelled to join forces (Wooldridge 2020).

Couples working together represent a unique form of business that is worth studying separately. This is so for many reasons and from different perspectives; for example, it is a widespread type of business, it represents a distinct business team, and it can be seen as a distinct type of family business. Data from different sources show that one in four businesses involves couples (e.g., US, UK, and France). As a business team, couples stand out because of their possibility to perform business duties and household duties flexibly and to bring tensions from home to work (Brannon et al. 2013). As a family business, couples are different from other family constellations because they share life goals (e.g., buying a house, raising children) that other family members do not share (Yang and Danes 2015). Although its distinctiveness is obvious, this particular business team and family constellation is rarely examined (Bird and Zellweger 2018). In many cases, the influence of couples on a firm is overlooked (Hamilton 2006; Hatak and Zhou 2019; Howorth et al. 2010) because life partners are often considered "invisible actors" (Cruz and Hamilton 2019).

This study was motivated by the observation that research and knowledge on couples working together in business is dispersed and lacks cohesion. The phenomenon has been studied across different bodies of literature and research streams, such as management, economics, psychology and sociology. The respective disciplines, although investigating the same phenomenon, have different research approaches and perspectives and use different terminologies. In this study, we use the term couple business to describe the phenomenon. Noticeably, a comprehensive review of empirical research on couple businesses is lacking. The 
aim of our study is to collect, summarize, synthesize and interpret the existing empirical findings on couple businesses. We conduct a systematic review of 71 articles on couple business guided by three questions: 1 . What is a couple business (descriptions)? 2. Where does it come from (antecedents)? 3. Where does it lead (outcomes)?

The empirical findings on couple businesses are both intuitive and counterintuitive. The descriptions of couple businesses are intuitive, and the findings tell us that the boundaries between work and family domains can be blurry and provide flexibility to specify business and household duties jointly. Tensions can move from one domain to the other, and the distribution of roles and power between the couple often follows gendered social norms. The antecedents of couple businesses can be intuitive as well, and the reasons that bring couple businesses into existence are diverse, ranging from complementary competencies of the partners to the lack of other work opportunities for one partner. Counterintuitive to popular thinking are the outcomes of couple businesses, which can sometimes outperform other types of businesses in economic terms.

The remainder of the article is structured as follows. We first provide a conceptual background; then, we discuss our review methodology and report our findings in two chapters. Finally, we provide a detailed and comprehensive research agenda for future research on couple businesses.

\section{Conceptual background}

This chapter provides the conceptual background for our literature review. We define the term couple business, we explain when a couple business is a family business, and we argue why couple businesses are a unique form of business.

\subsection{Definition of the term "couple business"}

The literature uses different terms to refer to the phenomenon of couples working together. Some examples are family business-owning couples (Danes and Morgan 2004), entrepreneurial couples (Brannon et al. 2013), copreneurs (Barnett and Barnett 1988), and couple-run companies (Machek and Hnilica 2015). These terms alternate between the couple and the business as a unit of analysis. In this paper, we use the term couple business to be consistent-by considering the business as the unit of analysis - and concise - by using a two-word term that is not easily confused with other terms. The term copreneur, for example, can be easily confused with coentrepreneurs, which means two partners-who are not necessarily romantic partners-running a business together.

We define a couple business as "a business where a romantic couple owns and/ or runs a business together". The couple can be cohabiting or married and can be mixed or single gender. Both partners can coown the business or be actively involved in the management of the business. Most importantly, they both have a sense of (psychological) ownership of the business. The latter point also distinguishes couple 
Fig. 1 Relationship between the family business and the couple business definition when the family business definition does not include succession (intention)

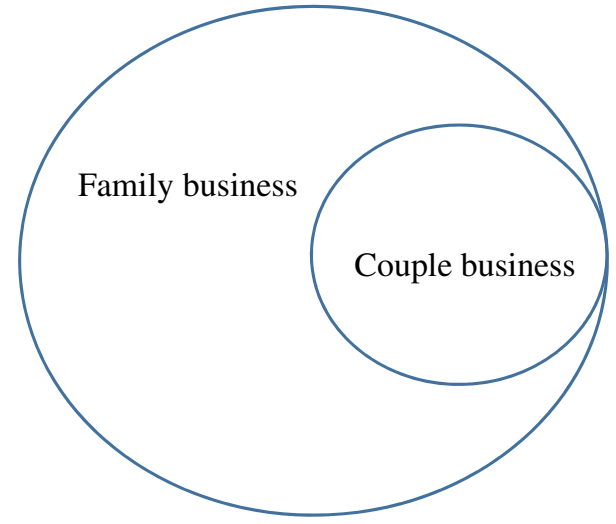

businesses from businesses where one partner owns and runs the business and the other assists him or her as a helping family member (Block et al. 2014, 2015). Our definition is irrespective of sector, firm size, and firm age. Additionally, business succession or the intention of business succession is not a necessary condition. ${ }^{1}$

\subsection{Is the couple business not a family business?}

Depending on the exact definition of family business, ${ }^{2}$ a couple business may or may not be seen as a family business.

When the family business definition is delimited to family influence via power (including ownership, management and governance) and does not include succession or succession intention, the couple is regarded as a family having influence over the firm (Fig. 1).

When the family business definition encompasses family succession or at least succession intention, the situation becomes more complex. In this case, only those couple businesses where succession or succession intention exists can be seen as family businesses. Hence, three cases exist (Fig. 2): family businesses that are not couple businesses (case I), couple businesses that are also family businesses (case II), and couple businesses that are not family businesses (case III).

\subsection{How many businesses are couple businesses and what makes them unique?}

Couple businesses represent a significant proportion of businesses. Statistics from multiple sources report that at least one-quarter of new businesses involve couples, namely, in the US (National Federation of Independent Business 2002), the UK (Shared Business Service 2006), and France (New Enterprises Information System

\footnotetext{
1 This definition joins the typology developed by Fletcher (2010), which we will present later when reporting the results of our review.

${ }^{2}$ For a detailed review of the different definitions of family businesses, refer to Astrachan et al. (2000).
} 


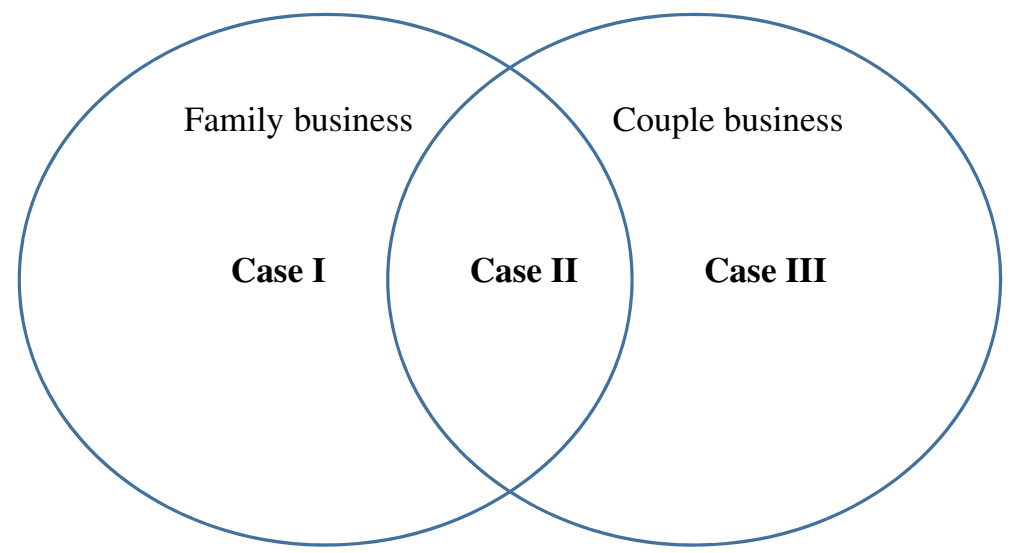

Fig. 2 Relationship between the family business and the couple business definition when the family business definition includes succession (intention)

2002; 2006). In Australia, couple businesses are reported to be numerous and growing (Smith 2000); similarly, in the US, figures are surging (Venter et al. 2012).

A couple in business together is distinct from other business teams because they have particular behavioral norms and expectations associated with role identities; sharing the business and the household comes with the flexibility to perform the duties associated with these domains jointly and with the permeability of tensions from one domain to the other (Brannon et al. 2013). When the process of life-making and business-making is one and the same process, the couple in this situation has a different experience than dual-career couples (Fletcher 2010) or other spousal roles in the firm (Poza and Messer 2001).

As a family business, a couple-run business is distinct from other family businesses. A life partner, although considered family (Westhead et al. 2002), is not blood related and is voluntarily chosen (in most cases), in contrast to other family relations, such as parents and children, siblings and cousins. In addition, a couple shares not only the same firm but also the same household and life goals. In other types of family businesses, there might be one business, but there are often multiple households and different life goals.

\section{Review method}

The principles of a systematic literature review methodology are transparency, clarity, equality and accessibility (Pittaway and Cope 2007). The process is reported openly, similar to the clear description of methods in empirical research. The main contribution of our review is the synthesis of empirical findings on couple business research. What once constituted a fragmented body of research scattered across different subject areas is compiled and presented as one homogenous line of research. 
We follow the three stages of the systematic review method outlined by Tranfield et al. (2003): planning (Sect. 3.1), conducting (Sect. 3.2) and reporting (Sects. 4 and 5 ). We consolidate the results of the identified empirical studies about the couple business by ultimately relying on a qualitative analysis of the results. To do so, we rely on a set of predefined concepts and protocols to identify the studies and on predefined categories to derive the pertinent information from the studies. Then, we use pattern matching and explanation building as techniques for qualitative analysis of the findings. In pattern matching, which is not a precise science, researchers look for matches and mismatches; even an "eyeballing" technique is sufficiently considerable to draw a conclusion in such research (Yin 1994, p. 110). The pattern matching and explanation building follow an iterative fashion until agreement between the authors is reached.

\subsection{Planning the review}

The purpose of the planning stage is to delimit the conceptual part of the research protocol and define the technical parts of the protocol. To do so, we discuss the research problem and its significance; we define the concepts and establish some guiding questions to assist in the preliminary organization of the findings. The guiding questions are as follows: 1. What is a couple business (descriptions)? 2. Where does it come from (antecedents)? 3. Where does it lead (outcomes)?

The technical part of the protocol relates first to the type of documents we are looking for and the outlets where we can find them. We confined our sources to academically validated knowledge, viz. peer-reviewed journal articles. The review methodology deliberately disregarded journal impact rankings as a selection criterion to reduce the risk of valuable missing studies. The databases ABI ProQuest and Business Source Premier were used, as they are two of the most comprehensive databases of peer-reviewed journals in the social sciences. These two databases were also chosen over other databases (e.g., JSTOR, ScienceDirect, and Scopus) because they provided the largest number of studies in searches using the broad keywords "copreneur*", "life partner*" or "spouse*" AND "business*". The search was not restricted with regard to the time period in which a study was published.

At this stage, we also established the keyword search strings, the exclusion and inclusion criteria, and a prefilled Excel worksheet to aid in depicting the relevant data from the studies.

\subsection{Conducting the review}

To capture the empirical literature on couple businesses, we used two sets of keywords: the first referred to "life partner", and the second referred to "business" (“Appendix Table 2"). We chose keywords broad enough to capture all publications suggesting that life partners run a business together because we recognize that there are multiple terms referring to the same phenomenon. The keywords had to be featured in either the title or the abstract of the study. Each database was probed using the same search string as reported in "Table 2 of the Appendix", along with 
the search dates and number of returns recorded. The total number of returns using these search strings was 6684. From this total number of returns, duplicate studies were removed. In an iterative process, these results were reviewed against the inclusion and exclusion criteria ("Appendix, Table 3") using title and abstract analysis. This process reduced the number of potentially relevant articles to 255 . Since the keywords are broad, it is understandable to have a large number of irrelevant articles. To further reduce the list of relevant studies, one author and one external researcher separately conducted a thorough review of the abstracts and keyword search against the inclusion and exclusion criteria. The intercoder reliability in terms of common agreement was $89 \%$. Disagreements between the coders were discussed until an agreement was reached. This step brought the number of relevant articles down to 61 .

In the next step, to capture other potentially relevant publications that could have been missed in our systematic database search, we screened the backward and forward citations of the five most recent articles and the five most-cited articles in our list of 61 articles. For example, two of the most-cited studies are Ruef et al. (2003) and Chell and Baines (1998), and one of the most recent articles is Madanoglu et al. (2020). Overall, this step culminated in the addition of six articles, ${ }^{3}$ one of which is a conference paper that we deemed relevant to recent discussions on the topic.

The systematic research captured articles from diverse subject areas (viz. family business, entrepreneurship, labor economics, family science, and sociology), but we noticed that agricultural economics journals were somewhat underrepresented. Our assumption was that couple businesses are typical in the farming sector. Hence, we reviewed relevant agricultural economics journals selected from the Harzing List 2016 (e.g., Agricultural Economics; American Journal of Agricultural Economics). We used a slightly different search protocol because we assumed that these journals employ specific terms such as farm instead of business. This search yielded four additional articles. Hence, the total number of articles included in our review comprises 71 articles (“Appendix, Tables 4 and 5").

\section{Descriptive overview of the field}

To report on the 71 articles, we used an Excel worksheet that includes descriptive information ${ }^{4}$ as well as thematic elements ${ }^{5}$ related to our guiding questions. The coding was conducted by one author and one external researcher. Each researcher coded the 71 articles separately and independently (agreement between coders: $92 \%)$.

\footnotetext{
3 These articles are Fu (2020), Dahl et al. (2015), Butler and Modaff (2012), Harris et al. (2007), Hamilton (2006) and Danes et al. (2005).

4 Examples include authors' affiliations, journal, subject area, definition of couple business, research question, main findings, literature bases, theory, characteristics of the sample, and methods.

5 Some examples of these elements are descriptions/antecedents/outcomes, definition of the couple business, and main findings.
} 
Our descriptive overview reports on the operationalization of the couple business, the samples and units of analyses used, the research methods employed, the literature bases and theories used, the research evolution of the field, and the publication outlets.

\subsection{Operationalization of the couple business}

How did the studies in our review operationalize couple businesses? Most studies briefly defined a couple business using one or more of the following dimensions: ownership, management and relationship type. More than two-thirds of the articles included the management dimension in their definition, for example, "couples that share responsibility, commitment to a business" (Poza and Messer 2001) or "couples in business together" (Muske and Fitzgerald 2006). More than half of the studies used the ownership dimension, for example, "firms owned by a married couple" (Belenzon et al. 2016) or "people married or living together jointly owning the business" (Baines and Wheelock 1998). Almost half of the studies used both management and ownership to define couple business. Almost two-thirds of the studies in our sample confined their definition to couples in a marriage relationship; eight studies included the term "cohabiting". The other studies were broader in using the term "couples". Two studies accounted for divorced couples. Only two studies were clearly inclusive of same-gender couples. More than half of the studies reported solely on heterogeneous couples, and the rest were not specific about this aspect.

Fitzgerald and Muske (2002) as well as Muske and Fitzgerald (2006) developed the most specific operationalization: organizations are considered to be couple businesses if (i) the business manager is married or pseudomarried; (ii) the household manager is the life partner of the business manager, works in the business and is acknowledged to do so by the business manager without a specification of the number of hours worked; and (iii) the life partner is considered to be a main decisionmaker. Notably, no coownership criterion is applied.

The couple business identity was another approach used to operationalize the couple business. According to Danes and Jang (2013), the copreneurial identity is formed when an entrepreneur's appraisal of his or her life partner's commitment is congruent with the life partner's self-assessment of commitment.

\subsection{Samples and units of analyses}

The sample sizes and units of analysis in the studies varied from one couple to 1300,000 firms. The majority of the sample sizes were between 60 and 400 units of analysis, and they were either all couple businesses or only partly so. The unit of analysis varied from firms to couples, teams, households, and individuals. Data sources varied from convenience samples obtained from networks to large public 
databases that provided longitudinal data. In terms of sector, almost half of the studies included different sectors; the rest mostly used samples from the farming, hospitality and retail sectors. Only a few studies have focused primarily on knowledge-intensive industries, such as information and communication technology, law or business services. Almost $10 \%$ of the studies did not specify the sector under investigation. Moreover, almost half of the studies reported primarily on microfirms (fewer than 10 employees $^{6}$ ), and $37 \%$ did not provide any information about business size. The rest either focused on small, small and medium, medium and large, or only large firms or reported on all firm sizes. The research appeared to be biased towards small couple businesses and did not seem to reflect their diversity proportionally. Although business age was seldom reported, most studies seemed to report on couples as the founding team of the business. No study mentioned a takeover after succession per se. In this respect, previous research on couple business has focused mostly on the emergence of new businesses. Additionally, the studies have reported on businesses on all continents. However, there is a country bias towards the US (more than $50 \%$ of studies), followed by the UK ( 8 studies), the Czech Republic, South Africa and New Zealand (3-4 studies each ${ }^{7}$ ); the other studies have reported mostly on other European countries and a few countries from the remaining continents. Only four studies have been comparative; that is, they reported on more than one country.

\subsection{Research methods}

In terms of methods, $70 \%$ of the studies employed quantitative methodologies, including seven studies using mixed methods. The majority of these studies emphasized theory testing (30 studies), and the rest were either descriptive or exploratory. Accordingly, the analyses varied from descriptive statistics and regression models to a few studies with structural equation modeling and factor analysis. The remaining $30 \%$ of the studies used solely qualitative methods, mostly exploratory. One noteworthy observation is that research from the US was predominantly quantitative and that studies with UK samples were mostly qualitative, which is consistent with previous findings in entrepreneurship research and reflects context-specific research traditions in methods (Welter and Lasch 2008). A similar observation was noted, for example, in a review of research on small firms; i.e., US research leans towards quantitative empirical methods, while UK research towards qualitative empirical methods (Macpherson and Holt 2007).

\footnotetext{
${ }^{6}$ Following the European Commission Recommendations (2003), microfirms are defined as those with 0-9 employees, small firms are defined as those with 10-49 employees, and medium-sized firms are defined as those with 50-249 employees.

7 Generally led by the same author(s).
} 


\subsection{Literature base and theories}

Most of the studies relied on multiple literature bases, with nearly half using entrepreneurship or family business. One-third used gender-related literature (e.g., gender power dynamics, gender roles, and gendered discourse), and more than $10 \%$ used family science or small- and microfirm literature. Other literature bases used included organizational behavior, economics, agricultural studies, corporate governance, and strategic management. Unsurprisingly, the literature base was consistent with the journals in which the studies were published.

In terms of theory, many studies employed system models of family business that consider business and family systems as one system: the family fundamental interpersonal relationship orientation (family FIRO) and the sustainable family business model (SFBM). All the studies that used the family FIRO model as a framework featured the work of Danes et al. (2002), which suggests that she is the leader in applying this model to study couple business. Briefly, the family FIRO model (Doherty et al. 1991) is a theory of human dynamics and change that adopts a systemic view of family business and describes the developmental sequence of the formation and history of family businesses. The model includes three dimensions: inclusion (structure, commitment, and shared meaning), control (dominating, reactive or collaborative) and integration (achievement of family business goals). The items of the first dimension affect those of the second dimension, which in turn affect those of the last dimension. The theory argues that business and family systems overlap in terms of needs, constraints and processes and that the success or failure of each system inherently influences the other (Stafford et al. 1999).

Finally, a few studies referred to standard management theories such as the resource-based view or agency theory. The remaining studies used united career theory, entrepreneurial network theory, identity theory, meritocratic logic, and a family embeddedness view.

\subsection{Research evolution and relevant journals}

The oldest article in our review list was published in 1971, and the second oldest was published in 1984. Five articles were published in the nineties, and most of them were published in entrepreneurship journals. Between the nineties and the first decade of 2000, the number of publications increased seven-fold, led by family business and family science journals. The number of publications increased by $10 \%$ in the last decade compared to the first decade of the 2000 s, with publications in entrepreneurship taking the lead, followed by family business. In addition, although this paper does not focus on bibliometric data, the leading author in this stream of research is Sharon Danes, who authored 20\% of those articles (14 out of 70). She was the first author for eight articles and was predominantly published in family business and family science journals. These studies were published in a wide array of journals that are mostly US-based, namely, Family Business Review (10 studies), International Small Business Journal (4), and Family Relations (3). The remaining studies were dispersed across journals such as Entrepreneurship Theory and Practice, American Sociological Review, and Human Relations. Notably, the 
leading general management and business journals, such as Administrative Science Quarterly, Academy of Management Journal and Journal of Management (Studies), did not appear in our list, perhaps because top-tier journals are biased towards large organizations (Macpherson and Holt 2007), while research on couple businesses seems to be focused on small businesses.

\subsection{Concluding remarks}

Overall, the operationalization of the concept is not consistent in the literature. The only necessary condition that all studies agree upon is the couple relationship. However, even on this one concept, the research is clearly biased towards heterosexually married couples and does not properly reflect the diversity of couples that exist, such as cohabitating couples and same-sex couples who are married or cohabitating. Previous research has demonstrated that different ties (e.g., cohabitation, marriage, and divorce) differentially affect the transition to self-employment (Ozcan 2011). Moreover, the research is concentrated on developed countries and lacks multicountry studies. Most striking, however, is the proportion of US samples, which is probably due to author affiliations and a presumed US bias in early entrepreneurship and family business research (Parker 2018). This tendency may distort the image depicted in our literature review and confines it largely to North American or, more generally, Western contexts. In addition, interestingly, while each study builds on at least one stream of literature, more than half of the studies used no specific theory. Finally, despite the constant rise of publications and the importance of the phenomenon, there is not one publication in the leading general management and business journals.

\section{Findings and future directions}

In this section, we report on the studies' findings and at the same time provide directions for future research. The section is organized around our three guiding questions: 1. What is a couple business (descriptions)? 2. Where does it come from (antecedents)? 3. Where does it lead (outcomes) $?^{8}$ Table 1 summarizes the entire section.

\subsection{Descriptions of the couple business}

Twenty-eight of the 71 identified studies fall into this category. In organizing the findings, three themes emerged within the descriptions of couple businesses: conceptualizations of couple businesses, work-home boundaries and gendered power differentials. ${ }^{9}$

\footnotetext{
8 These three categories (descriptions, antecedents and outcomes) are not discrete. For example, some studies focus on both: why do couple businesses start in the first place, and how do they organize themselves? Some studies even provide answers to all three questions. As such, some studies count in more than one category.

9 These categories are based on discussions between the authors. As explained in the method section, the choice of categories is based on pattern matching and explanation building, which followed an iterative fashion until agreement between the authors was reached.
} 


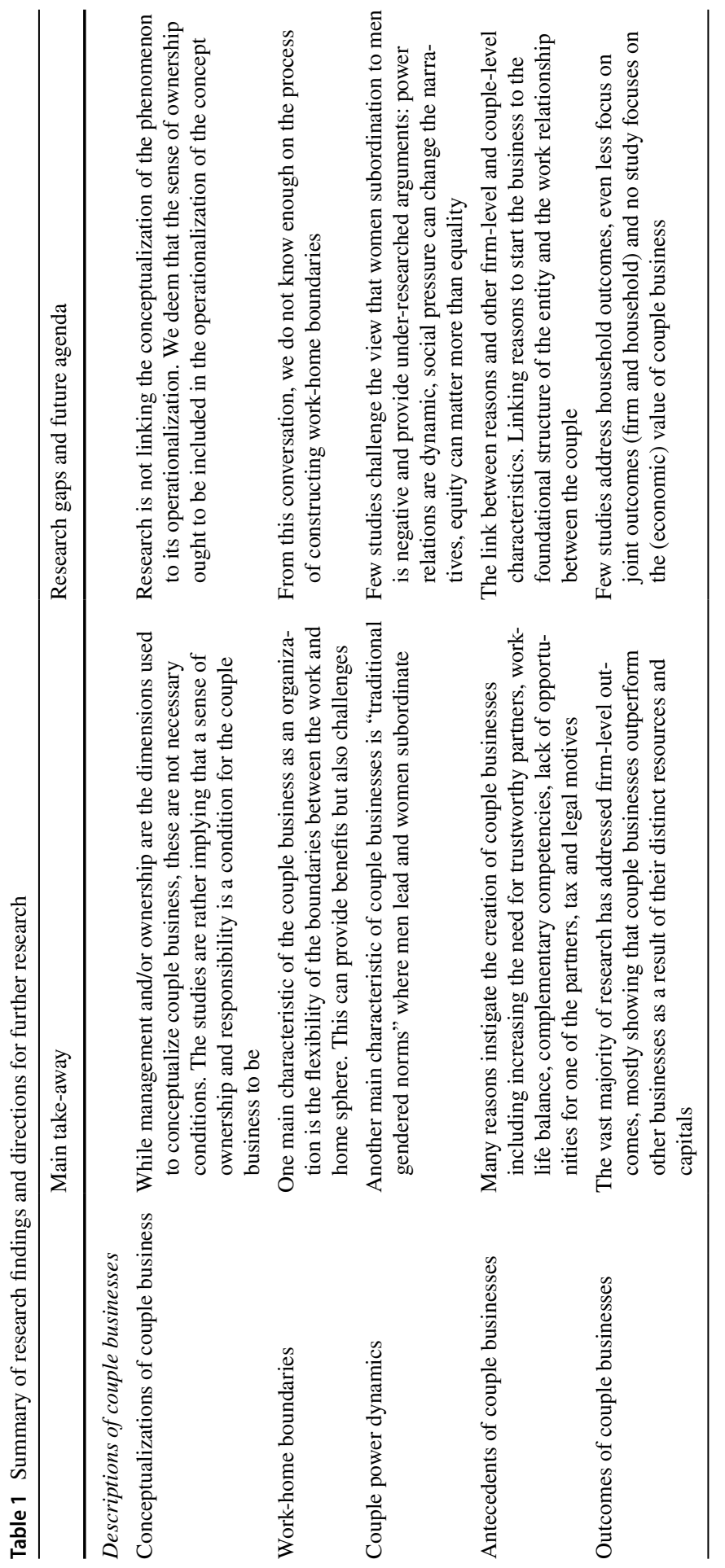




\subsubsection{Conceptualizations of couple businesses}

According to the typology of spousal roles in family business developed by Poza and Messer (2001), in couple businesses, the spouse differs from other types of spousal roles in their sense of ownership to the business (Poza and Messer 2001). Fletcher (2010) developed a typology of couple businesses based on management and ownership dimensions. "Copreneurial ownership" is when the couple jointly owns the business, but only one partner is involved in the day-to-day business operations. "Copreneurial management" is when both life partners are active in the business but both do not own the business. Under this classification, copreneurs can each manage a separate business and support each other by exchanging knowledge (Parker 2014). When both life partners are involved in management and ownership, it is considered "classic copreneurship". The last type is "intergenerational copreneurship", which is when the couple shares management or ownership and the firm has undergone a succession, which makes it linked to wider family relations. Most importantly, Fletcher (2010) provided a conceptualization of couple business, where, like Poza and Messer (2001), she highlighted the sense of ownership as an essential condition; i.e., "Co-preneurship is constructed through the market work of the household. It is characterized by the alignment of creative interests, knowledge, labour or skills with one's spouse, which are assessed as having commodity or market value and which lead to the creation (or repositioning) of an organizational entity. In addition, the couple shares commitment to and responsibility for the business venture in terms of risk, ownership and management and enact this in their life together" (Fletcher 2010, p. 466).

Future research directions Only two studies aimed to conceptualize couple business based on empirical data, which explains why the operationalization of the concept is diverse and sometimes vague, as demonstrated in our overview of the field. While being a couple is an essential condition in couple businesses, ownership and management are not. However, from the above discussion, the sense of (psychological) ownership to the business stands out as an essential condition; however, this condition is not operationalized in the vast majority of the studies. ${ }^{10}$ We believe that future research could achieve higher conceptual and methodological rigor by including this "sense of ownership" in the operationalization of couple business.

\subsubsection{Work-home boundaries}

Moving between work and home domains is central to the description of couple businesses. The possibility of blurring the boundaries between business and household comes with benefits and challenges.

Flexibility is an asset. An Australian-based study of 20 couples explained that autonomy, personal control, and family-friendliness account for the relative

\footnotetext{
${ }^{10}$ The few studies that accounted for the sense of ownership in their operationalization are Fitzgerald and Muske (2002), Muske and Fitzgerald (2006), and Danes and Jang (2013), as mentioned in Sect. 4.1.
} 
ease with which couple businesses can combine work and family (Smith 2000). Using a US-based sample, Epstein (1971) concluded that couples running law firms together can harmoniously meet work and family obligations by making the worksite at home or close to home. Similarly, a study of 600 US-based couples from multiple industries found that couple businesses tend to be small homebased businesses in rural areas; these couples tend to view the business as a way of life rather than a lucrative activity (Fitzgerald and Muske 2002), and they tend to intermingle the financial resources of the family and the business (Muske et al. 2009). Similarly, based on nine case studies from different developed countries, Andersson et al. (2002) revealed that couple-run rural accommodation businesses focus primarily on family goals and value lifestyle over economic gains. In this study, couple businesses make a living while prioritizing staying in the same location, assuming little or no debt, or keeping sufficient control over the business-all of which are boundaries that determine how much work can affect family life.

Tensions thrive in permeable boundaries. Making home the worksite can be challenging, especially in the commercial home as a business (hospitality sector) where family boundaries can be particularly permeable. One study using mostly a US-based sample described bed and breakfast couple owners as lacking personal time and private space and struggling to establish strategies to preserve work-home boundaries (Butler and Modaff 2012). This study found that couples employ traditional organizational structures by making the boundaries between the private and public spheres clear to their clients, whether by signage or communication, or they mentally resort to relying on future positive outcomes to sustain their current lack of privacy.

Setting boundaries is a strategy. When couples coconstruct their boundaries, it is very relevant whether the business is a main source of income or just extra revenue, with the former associated with fewer boundaries (Butler and Modaff 2012). Looking at pocket-money accommodation businesses in New Zealand, Harris et al. (2007) emphasized that over time, couples become more skilled in maintaining boundaries and preserving their work-life balance.

Future research directions Crucial to the conversation on work-home boundaries is the locus of business or the space where it takes place. The home-based business (e.g., accommodation business) has been a particularly fertile ground for studying work-family boundaries. Few studies have started exploring the strategies and structures set by couples to construct boundaries and moderate tensions. These studies have mentioned traditional organizational structure, cognitive methods (Butler and Modaff 2012), and the purposive intentions from the business that frame organizational goals (Andersson et al. 2002). Harris et al. (2007) suggested that time helps couples master the strategies needed to set boundaries that maintain work-life balance. Thus, as a process, setting boundaries between work and home is co-constructed by the couple. It depends on the antecedents of the couple business, aids in reaching certain outcomes, or creates unintended outcomes. It is dynamic, and couples get better at it over time. 
We believe that future research can advance the conversation on work-home boundaries by looking at a couple's co-construction of boundaries as a process. Some possible research questions include the following: Is there any life cycle for co-constructing their work-home boundaries over time? When is boundary setting strategic and to which strategy leads to which end? How do couples refine their strategies over time?

In terms of the theoretical framework, we first notice no mobilization of traditional organizational theories. For example, we suggest that boundary theory and work-family border theory are suitable for this topic. Boundary theory indicates that employees who keep their work and family roles separate have greater job satisfaction, less stress (Kreiner 2006) and better performance (Ashforth et al. 2000). For organizational employees, both family therapists and management consultants recommend separation (Ibrahim and Ellis 1994) and clear definition of boundaries (Rosenblatt et al. 1985) between work and family to avoid conflicts that emerge when the two systems meet. Work-family border theory explains how individuals cross the border between the domains of work and family and how the work-family balance is influenced by integration and segmentation, border creation and management, border-crosser participation, and relationships between border-crossers and others at work and home (Clark 2000).

\subsubsection{Gendered power differentials}

One-quarter of the 71 studies described the couple's power dynamics and highlighted gender differentials. Research shows that couple businesses reflect traditional gendered norms of men as "breadwinners" and women as "caretakers"; in business, men tend to focus on the present business, while women prioritize family relations (O'Connor et al. 2006; Jurik et al. 2019; McAdam and Marlow 2013; Bensemann and Hall 2010; Marshack 1994; Yang and Aldrich 2014; Danes et al. 2013; Ponthieu and Caudill 1993; Smith 2000; Chell and Baines 1998). Most studies depicted this as a negative characteristic of couple businesses, while few studies regarded it as complementarity between partners.

Women prioritize family. Narratives of an American and Czech sample of couple businesses (Jurik et al. 2019) and results from some 180 US-based firms (Danes 2006) showed that women mix business and care and prioritize good family relationships, while men's primary focus is the business. Using a European and American sample of 18 small and microfirms, Danes et al. (2005) observed that women use emotional language - they use "we" in their sentences and focus on ideas about the future and change-while men emphasize immediate tasks. Craft et al. (2015), based on a large US sample of small firms, indicated that women tend to be more optimistic about the effect of the new business on the spousal relationship and family finances, whereas men emphasize the possible negative effects.

Men demonstrate higher leadership over the business. A study based in New Zealand revealed that while women tend to ask for support, men assume or take for granted that they will receive support from their life partner (Kirkwood 2009). In some countries, such as the Czech Republic, men claim leadership over the business, whereas in the US, men attribute equal credit to women (Jurik et al. 2019). 
Even in women-dominated sectors such as food catering (Millman and Martin 2007), commercial homes (Bensemann and Hall 2010) or childcare (McAdam and Marlow 2013), when women have high levels of leadership, they still carry household responsibility, and men still express at least equal leadership in business.

Women have other considerations to take. In Millman and Martin's (2007) accounts, women as business leaders have to work hard to maintain work-family balance and protect their husbands from feeling undermined. Marshack (1994) argued that the traditional gendered division of work enables couples to set boundaries, which they need to have. The author added that this type of arrangement does not push the couple to re-examine their self-concept, including the matter of "who does what", as dual-career couples are forced to do to find family-work balance; in this way, couple businesses reinforce the traditional gender roles of women and men. One study indicated that the belief that couples cannot negotiate their roles without placing undue strain on their relationship leads some couples to resort to a stereotypical gendered division of tasks (Larsen 2006). Sometimes, women can pretend that men dominate; Hamilton (2006) explained that power relations within a couple are dynamic, being constantly negotiated and renegotiated, that dominance of men is often challenged in reality and that the subordinate role of women in business can sometimes be just an image portrayed for the outside world to align with cultural assumptions.

Equality is not necessarily 50/50. A few studies viewed the gendered distribution of power positively. A large US-based study showed that couples perceive that there is equality between them at work, including in decision-making (Cox et al. 1984). Deacon et al. (2014) suggested that life partners share responsibilities and complement each other on the basis of their individual competencies. While the authors in this study adopted a gender-neutral observation, the men and women in their sample also showed no resentment about the tasks they were performing, although women undertook most of the care work. Other studies also reported that women are satisfied with the distribution of tasks, but the authors described it as a subordination of women to men (Marshack 1994; Smith 2000). Ponthieu and Caudill (1993) described the roles of each partner as equal but different; they did not suggest that the value of decision-making in business is higher than the value of household responsibilities. Along the same lines, Wicker and Burley (1991) proposed that such configurations (gendered division of tasks) can be viewed as ways of coping with the conflicting norms of hierarchy and equality to reach the equity norm (where each partner is satisfied with the division of tasks). They suggested that the distribution of tasks between the couple in the business can be viewed as a strategy to reduce tension surrounding power-related issues in the couple business. As we will see in the outcomes section, conflict is diminished when each partner has a defined role and is satisfied with it.

Future research directions Research on couple business depicts a team where men dominate and women subordinate, both in the business and in the household. This representation of the power dynamics is articulated in terms of one's responsibilities, perceptions of one's role and the partner's role, or the authors' interpretation of what is an equal distribution of power. The discussion seems to suggest that the 
perceptions of these power dynamics can create tensions and conflict or synergies between the partners. As in any team, an uneven distribution of leadership is not surprising (Gould 2002; Lynn et al. 2009). These inequalities in business groups arise through mechanisms that are still poorly understood (Yang and Aldrich 2014), and the case of the couple team is no exception. We believe that the conversation on couple power dynamics is still at an exploratory stage; only 8 of the 18 studies that discussed power dynamics used a theoretical framework to analyze their observations (Craft et al. 2015; Danes et al. 2005, 2013; Danes 2006; Marshack 1994; Yang and Aldrich 2014; Hamilton 2006; Jurik et al. 2019). Moreover, the methods used further reduced the validity and generalizability of the findings — only two of these studies used multi-country samples. However, some studies have provided new insights, portraying a granular view of the patriarchal understanding of the power dynamics of couples in business. For example, Hamilton (2006) showed that power and gender relations do not have a fixed state but rather, "there are shifting forms of power constantly negotiated and renegotiated" (p. 268); respondents may want to align with the social assumptions, while in practice, women can be dominating. Wicker and Burley (1991) viewed this distribution of power as complementary and equitable because if both partners are satisfied with it, it can be viewed as a strategy to minimize tensions surrounding hierarchy.

As another avenue for future research, we suggest delving deeper into these propositions: power relations are dynamic, social pressure can change the narratives, the different meanings of equality. Which theories can be used to explain the propositions? For example, organizational theories explain the distribution of leadership and rewards using economic and meritocratic logic (Castilla and Benard 2010; Ladd and Bowman 1998; Meyer and Rowan 1977) and acknowledge gender logic as an implicit cultural rule (Ridgeway and Smith-Lovin 1999; Correll et al. 2007; Jurik 1998). In emerging and small businesses, the distribution of roles and power between team members is less formal (Shane 2008), and team members are likely to have pre-existing social relations (Yang and Aldrich 2014). For a couple business, the partners have a pre-existing romantic relation. Moreover, concerning gender, entrepreneurship research encourages the adoption of a feminist perspective to match the growing trends towards poststructural feminist approaches (Henry et al. 2016). Future research could build on existing theories used for gender and team leadership issues in research on organizations, entrepreneurship and family business and blend them with family theories (e.g., FIRO, SBMT, family communication patterns theory; Fitzpatrick and Ritchie 1994). We also encourage researchers to pursue more innovative methods leaning towards poststructural feminist approaches, such as sophisticated qualitative methods, ethnographies, and discourse analysis (Henry et al. 2016), where gender is viewed as a social construction operationalized as masculinity and femininity rather than as male and female (Ahl 2007).

In terms of research questions in this direction, we find the focus on perceptions to be particularly relevant, i.e., partners' perception of each other's share of power in the business and in the household. How do these perceptions form and evolve? Also important is the conversation about power distribution mechanisms. For example, how does leadership form and evolve throughout the different stages of the couple business? How is leadership negotiated and renegotiated within the couple as the 
business evolves? What are some strategies to reduce tensions arising from leadership matters?

\subsection{Antecedents of couple businesses}

Eleven of the 71 identified studies fall into this category; these studies revealed reasons why couples team up in business.

Couple business is good for the family. One US-based study indicated that couples choose to be in business together because they prefer trustworthy partners and inclusive approaches to making a living and meeting household needs (Ruef et al. 2003). Similarly, a study in the Czech Republic (Jurik et al. 2016) and a study based on a Canadian, Swedish and Australian sample (Andersson et al. 2002) reported the same work-life balance reasons. One US-based study noted that this self-selection depends on how satisfied couples are with their relationship (McDonald et al. 2017).

Couples start a business because they can be a good team. Another set of studies found that couple businesses are initiated because the partners have complementary competences (Nelson 1989; Kirkwood 2009), especially when the sector is knowledge intensive (Kuschel and Lepeley 2016). The ease and efficiency of sharing knowledge and information between couples improve their likelihood of joining forces in business and enable them to build synergies in managing the business and the home spheres (Parker 2014). One study based on 26 cases in the UK (Fletcher 2010) recalled most of the abovementioned reasons but also drew attention to the evolving nature of the relationship, i.e., starting as giving a hand in the business and shifting into a couple business.

Couples start a business because the market or institutional context calls for it. Some studies listed institutional and environmental reasons for the emergence of couple businesses. One Bulgarian-based study indicated that couples work together because of a lack of opportunities in the external environment (lack of start-up incubators and financing) and the cultural tendency of families to provide support (Fletcher et al. 2009). One Danish study aligned with these findings to some extent; Dahl et al. (2015) found that women in the lower income distribution have limited opportunities in the labor market and hence choose to team up with their spouse in business. One last institutional reason concerns the legal requirements for incorporating a business (O'Connor et al. 2006). While only one study noted this legal reason (an Irish-based study), it is reasonable to assume that this issue is applicable to many countries. Other similar reasons could include taxation motives. To date, however, evidence on these institutional antecedents is limited.

Future research directions The current body of research identifies many reasons to start the couple business (e.g., work-life balance, complementary competencies, lack of opportunities for one of the partners, and legal motives) but only makes suggestions on how these reasons affect the foundations of the business. We believe that future research could gain insight from linking the reasons to the foundational settings. The initial settings of a business can hint at the capacity to grow and the relational dynamic between the partners. Some couples start small and intend to 
keep their business small to maintain the work-life balance they sought when starting their couple business in the first place (Jaouen and Lasch 2015). Other couples start larger or want to grow, and this reflects in the way they run their business, how they evolve and how they behave with each other. We would expect, for example, that couples who have growth intentions tend to be more professional towards one another and have different perceptions of tensions or synergies than a couple running a business for lifestyle reasons (Jaouen and Lasch 2015). Thus, we encourage future research to link the reasons behind starting a business to the foundational settings of the entity.

\subsection{Outcomes of couple businesses}

Forty-three of the 71 identified studies fall into this category. These studies reported on some type of couple business outcome (firm-level, household-level, or both) and predominantly on firm-level outcomes, particularly financial success (17 studies). More than half of the studies used US-based samples, and only the US-based studies focused on household-level outcomes, with one exception. When another country was represented by more than one study (e.g., South Africa and the Czech Republic), it was likely that the studies were led by the same author(s). Only one study reported on multiple countries (Western Europe).

Financial and subjective business success The studies mostly focused on objective measures of financial success. ${ }^{11}$ The differential performance of couple businesses was examined in comparison to other businesses or other family businesses or among couple businesses. Overall, specific resources of couple businesses (often related to descriptors such as flexible work-home boundaries and gendered power dynamics) explain their differential performance levels.

Flexible work-home boundaries are resources that enable couple businesses to outperform nonfamily businesses and other family businesses, in most cases. In terms of start-up success, Brannon et al. (2013) found that couple teams had better chances than other entrepreneurial teams in achieving initial sales; they argued that the competitive advantage of couples resides in the meta-identity they develop, thereby enabling them to leverage family relationships and meet business and family obligations more flexibly. Using their home as a collateral enables couples to achieve higher business profits than other types of businesses (Muske et al. 2009). Especially when they are satisfied with their relationship, couples are likely to achieve greater profits than noncouple teams (McDonald et al. 2017). In the same vein, a Swedish study revealed that relational embeddedness-whose facets are trust, identification, and mutual obligations - is higher in couple teams than in sibling teams, and this

\footnotetext{
11 When subjective business success is used, it included business aspects, as well as some family-related aspects (For example, Farrington et al. 2011a, b, operationalize perceived success as follows: "Perceived success refers to the copreneurs finding their involvement in the copreneurship as satisfying and beneficial to their marriage relationship."). In the rest of the cases, the basis on which couples evaluate subjectively business success is unclear.
} 
factor in turn increases couples' likelihood of higher firm growth (Bird and Zellweger 2018). A large study in Western Europe explained the higher financial performance of couple businesses by citing conservative investment choices and differentiated strategic behavior (Belenzon et al. 2016). Two studies using the same sample from the Czech Republic showed that couple businesses perform better than other businesses in terms of profitability ratios (Machek et al. 2015), operating efficiency and debt levels (Machek and Hnilica 2015). Two UK-based studies using the same sample of microfirms in business services showed evidence of underperformance of couple businesses compared to other businesses in terms of turnover and the number of employees (Baines and Wheelock 1998; Chell and Baines 1998).

Blurred work-home boundaries are a source of tensions negative for business performance. Danes and Olson (2003) showed that the success of couple businesses is affected negatively by tension when it reaches a certain threshold. In alignment with these findings, a Taiwan-based study posited that work-family conflict is negatively related to business success since family boundaries are more penetrable than work boundaries (Wu et al. 2010). One US-based study found that using business cash for the family is negatively related to the feeling of success (Muske et al. 2009), and one Taiwan-based study found that work-family conflict is negatively related to perceived business success (Wu et al. 2010).

The couple is a source of tangible resources that explain performance differences among couple businesses. A Slovenian study of two couple businesses argued that the couple's higher level of networking explains business growth (Bratkovic and Antoncic 2009). A Taiwan-based study showed that the performance of coupleowned franchises is affected by franchisor resources and spousal resources (Chien 2014). Relatedly, Matzek et al. (2010) indicated that spousal resources enable a couple to retain financial resources that would otherwise be spent on hiring employees or paying for arm-length services.

The couple is a source of intangible resources translating into success. Yang and Danes (2015) showed that spousal commitment reduces the number of months needed to break even, which is a measure of new venture sustainability. Cole and Johnson (2007) found that emotional connection, compartmentalization, synergy, commitment to the business, and positive gender issues contribute to business success, as well as the business relationship between the partners, within a couple. South African data showed that the perceived success of couple businesses relates positively to a number of team structure-related elements (shared dream, leadership, personal needs alignment, complementary skills, supportive employees, competencies and adequate resources; Farrington et al. 2011b), as well as relational-based factors such as the spousal relationship, the presence of nonfamily members, commitment to the business, emotional attachment to the business and balance between home and work (Venter et al. 2009). US-based studies found that better communication leads to higher levels of congruence between self-assessments and each partner's appraisal of the other in terms of business commitment (Danes and Jang 2013), which in turn leads to higher perceived business success (Jang and Danes 2013). More broadly, one US-based study found that satisfaction with the business, which is another indicator of subjective business success, is linked to life partners' expectations of the joint business (Liang and Dunn 2009). Furthermore, a South African 
study revealed that satisfaction with the business is related to mutual trust, commitment to one's spouse, open communication, and work-family balance (Venter et al. 2012). One case study of Beckham's argued that a couple's success revolves around how they capitalize on their "familiness"- a resource that every family business owns - and turn it into an image-related resource based on the associations reflected by the family to external stakeholders (Parmentier 2011).

Other firm-level outcomes Other firm-level outcomes relate to survival, productivity, efficiency and (strategic) management outcomes.

Regarding business survival, studies with large samples of US and Western European firms of different sizes and industries showed that couple businesses are more likely to survive than other types of businesses (Madanoglu et al. 2020; Muske and Fitzgerald 2006; Belenzon et al. 2016), especially when they are home based (Madanoglu et al. 2020), have higher levels of employees and financial performance, and the couple is highly educated (Muske and Fitzgerald 2006).

In terms of the productivity and efficiency of couple businesses, the findings are diverse. One Italian study of family businesses found that couple businesses have lower employee turnover and better labor productivity (Amore et al. 2017). In a Czech context, Machek and Hnilica (2015) reached opposing results, finding that couple businesses perform worse in terms of labor productivity and asset-use efficiency. Hedberg and Danes (2012) argued that couple businesses are more productive in decision making when couples see each other as equal partners and engage in collaborative power interactions. A sense of inclusion and the manner in which control issues are managed seem to considerably affect family business integration because inclusion predicts control dynamics (Danes et al. 2002). Similarly, in the farming context, productivity has been found to depend on the allocation of work, specifically in given plots, to men and women within the couple (Andrews et al. 2014), and efficiency has been found to depend on credit constraints (Fletschner 2008) and relate to reduced gender disparities (Seymour 2017). Other management practices were found as determinants of economic well-being in farm households such as forward purchasing of inputs, use of contract shipping of products, or also having a succession plan (El-Osta et al. 2007).

Concerning strategic management behaviors, a study using a large Western European sample of firms demonstrated that couple businesses, in comparison to family and nonfamily businesses, use more conservative management strategies and other differing strategic behaviors that benefit their performance (Belenzon et al. 2016). Couple businesses tend to have unique investment strategies, as demonstrated by a large Italian sample (Amore et al. 2017), and they tend to pursue innovation and have greater innovation output than other businesses, as shown by a large sample of Chinese firms (Fu 2020).

Household-level outcomes Few studies have examined household-level outcomes (couple relationship, household income, the impact of business on the family, workfamily conflict, perception of tensions), and all of them have used US-based samples, except one Taiwanese study. Even fewer studies have examined both firm-level 
and household-level outcomes simultaneously (Danes and Morgan 2004; Jang and Danes 2013; Wu et al. 2010; Matzek et al. 2010; Dyer et al. 2012).

Some research has indicated that couples teaming up in business positively affects the relationship quality of a couple (Matzek et al. 2010), household income (Dyer et al. 2012; Cox et al. 1984), income inequality in the household (Dahl et al. 2015) and eventually other household expenditures, such as health care (Mishra et al. 2012). Couples that have better business-related communication also have higher expectations from the business regarding its impact on the family (Jang and Danes 2013). Couple businesses who survive the first 2 years perceive that their business has a positive impact on their marital relationship (Wicker and Burley 1991). A South African study showed that when leadership, needs alignment and role clarity are in order, the couple is more satisfied with their relationship (Farrington et al. 2011a). A Taiwanese study found that the couple relationship is negatively related to work-to-family conflict (Wu et al. 2010). Helmle et al. (2014) found that perceptions of work-life conflict are affected by how flexible the partners are in communicating about work at home and how permeable this communication is.

Tensions and conflict emerge from power distribution and work-home boundaries. Danes delved deeper into the subject of conflict by demonstrating a gendered sensitivity to tensions. For women, business tensions increase with their role dissatisfaction when their husbands identify them as the main decision makers (Danes and Morgan 2004), and this negatively affects their feeling of satisfaction with their spouse (Amarapurkar and Danes 2005). For men, tensions increase because of the experiences of stressful life events, the emphasis placed on keeping the business within the family (Danes and Lee 2004), and the longer hours worked by their wives in the business (Danes and Morgan 2004). For both women and men, tensions are triggered by having preschool children and by an unfair distribution of resources between family and business systems (Danes and Morgan 2004; Danes and Lee 2004). The studies also found that tensions are soothed when the family has a high level of functional integrity (e.g., family success in terms of their adaptation, partnership, growth, affection and resolve), when husbands place family before business, and when wives are satisfied with their role (Danes and Lee 2004).

Future research directions Existing research has shown that couple businesses can outperform other businesses as a result of their distinct resources and social capital. In this regard, it would also be interesting not only to focus on performance as a final business outcome but also on strategic mechanisms, organizational designs and intermediate business outcomes. For example, how do couples businesses as entrepreneurial team ventures compare to other ventures with regard to (Schumpeterian) innovation (Block et al. 2017)?

Despite the clear importance of the family or household component in couple business research, few studies have actually examined household outcomes (almost all were US samples), and even fewer studies have examined both business and household outcomes jointly. Clearly, investigating household outcomes and joint outcomes of couple businesses are promising avenues for research, 


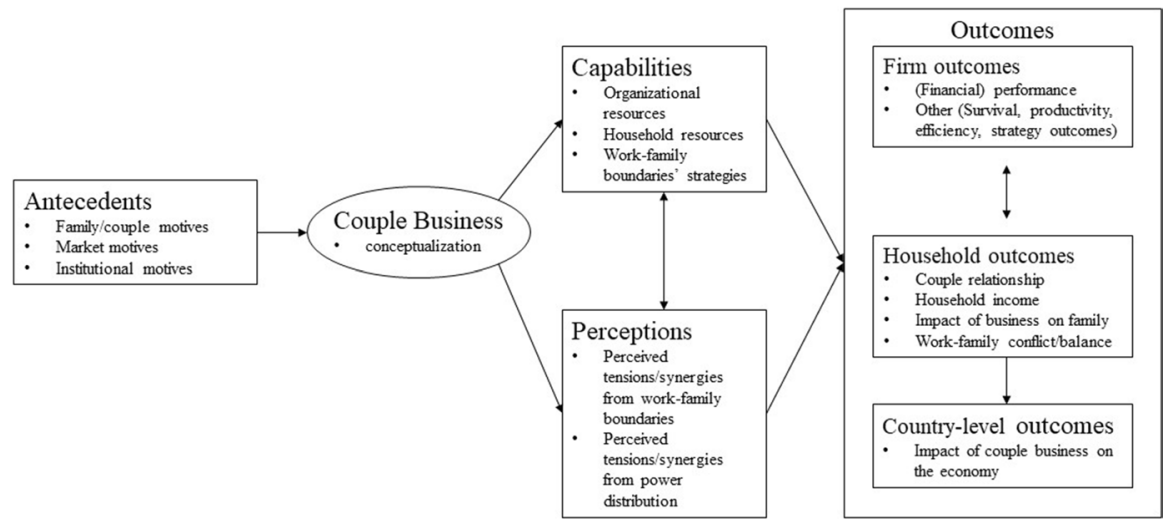

Fig. 3 Conceptual framework

particularly for family business research. The couple business can be viewed as the simplest unit to study the genesis of family businesses (Blenkinsopp and Owens 2010; Fletcher et al. 2009). It is easier to study two systems jointly when there is one of each system and the agents are the same in each. A couple business has one business and one household, as opposed to other family businesses where there is one business but multiple households (e.g., household of the parent, child, and cousin). As such, we could suggest many research avenues in this line of thinking. For instance, to further explain the differential performance of couple businesses, we encourage researchers to extend the examination of their distinct capabilities from a strategic management perspective. Another avenue is to explore how these capabilities change over time as they interact with affect (i.e., the perceptions of each partner about work-home boundaries and power distribution). Such topics interest the larger family business audience (Salvato and Aldrich 2012) and the dual-career couples' audience, given the rising trend of working from home during the coronavirus. Additionally, household outcomes relative to upbringing is another avenue. Entrepreneurship research has demonstrated that growing up in an entrepreneurial family increases the probability of engaging in entrepreneurship (Eagly 1997; Laspita et al. 2012), while strategic management research shows that children of CEOs may have similar decision-making tendencies (Schoar and Zuo 2011). Some possible research questions include how children perform at school with different settings of work-home boundaries and different distributions of power between the parents.

With regard to country-level outcomes, exploring such outcomes should also be explored in future research. We have seen that the couple business is a widespread type of business, representing at least one-quarter of new businesses (De Bruin and Lewis 2004; Dyer et al. 2012; Fletcher 2010; Muske and Fitzgerald 2006; Ruef et al. 2002), and its impact on the economy may be significant. However, we did not identify any country-level outcomes in our review of the literature. Future research may provide a better understanding of this phenomenon 
by exploring the aggregate economic effects of couple businesses at regional or country levels.

\subsection{A cohesive model that puts everything together}

When we try to put everything in concert together, the relationships can be summarized as shown in Fig. 3. A variety of motives bring couple businesses into existence. Couple businesses have generic capabilities in addition to specific capabilities, including work-family boundary strategies, such as flexibility in specifying business and household duties, and intermingling resources of household and business. These capabilities lead to certain perceived tensions or synergies (e.g., negative perception of distribution of power), which can change over time and lead to a change in business strategy. These capabilities and perceptions, in turn, lead to outcomes (i.e., firm-level, household-level, and hopefully research will tackle country-level outcomes in the future).

\section{Conclusion}

In this study, we systematically reviewed 71 articles on romantic couples running a business together, i.e., "couple businesses", which is a phenomenon that has been studied in different disciplines, thereby making the literature base fragmented. We provided a structured overview of the current state of empirical research on couple businesses. The review culminated in a cohesive story of the empirical research, an agenda for future research and a model putting together the different pieces. We hope this review provides structure for future researchers. We believe that the phenomenon of couple business warrants further scholarly attention as a widespread and distinct form of business that sprouts many family businesses and potentially as a way for couples to make a living symbiotically with other aspects of their lives.

Acknowledgements Montpellier Business School (MBS) is a founding member of the public research center Montpellier Research in Management, MRM (EA 4557, Univ. Montpellier). Frank Lasch is a member of the LabEx Entrepreneurship (University of Montpellier, France), funded by the French government (Labex Entreprendre, ANR-10-Labex-11-01).

\section{Appendix}

See the Tables 2, 3, 4 and 5. 


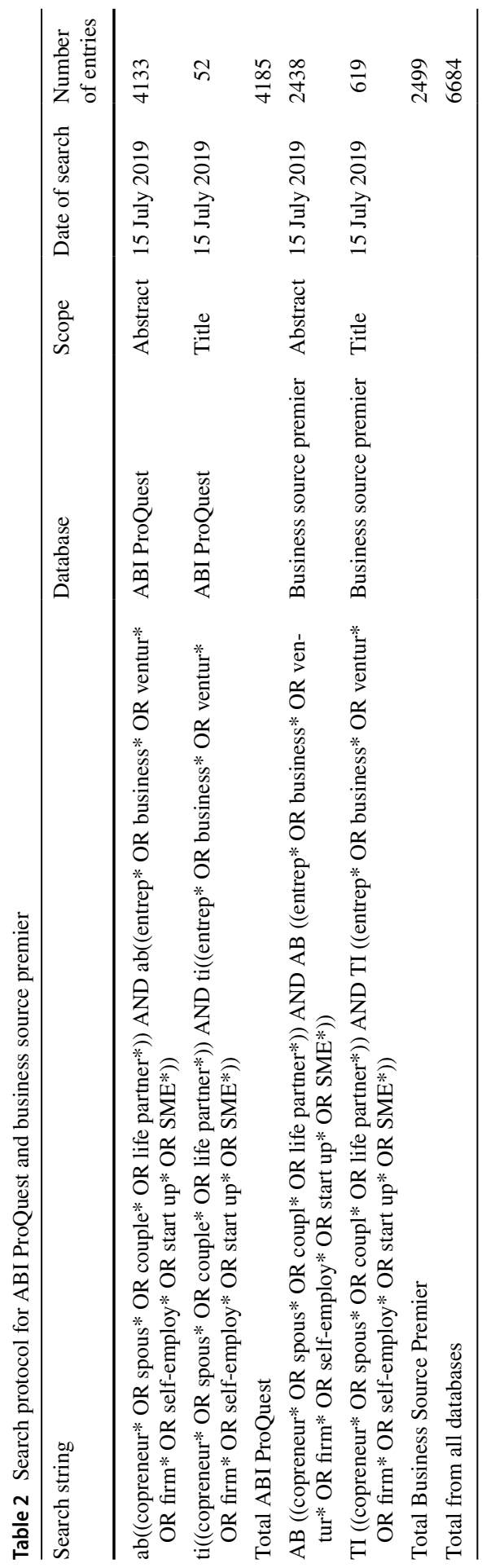




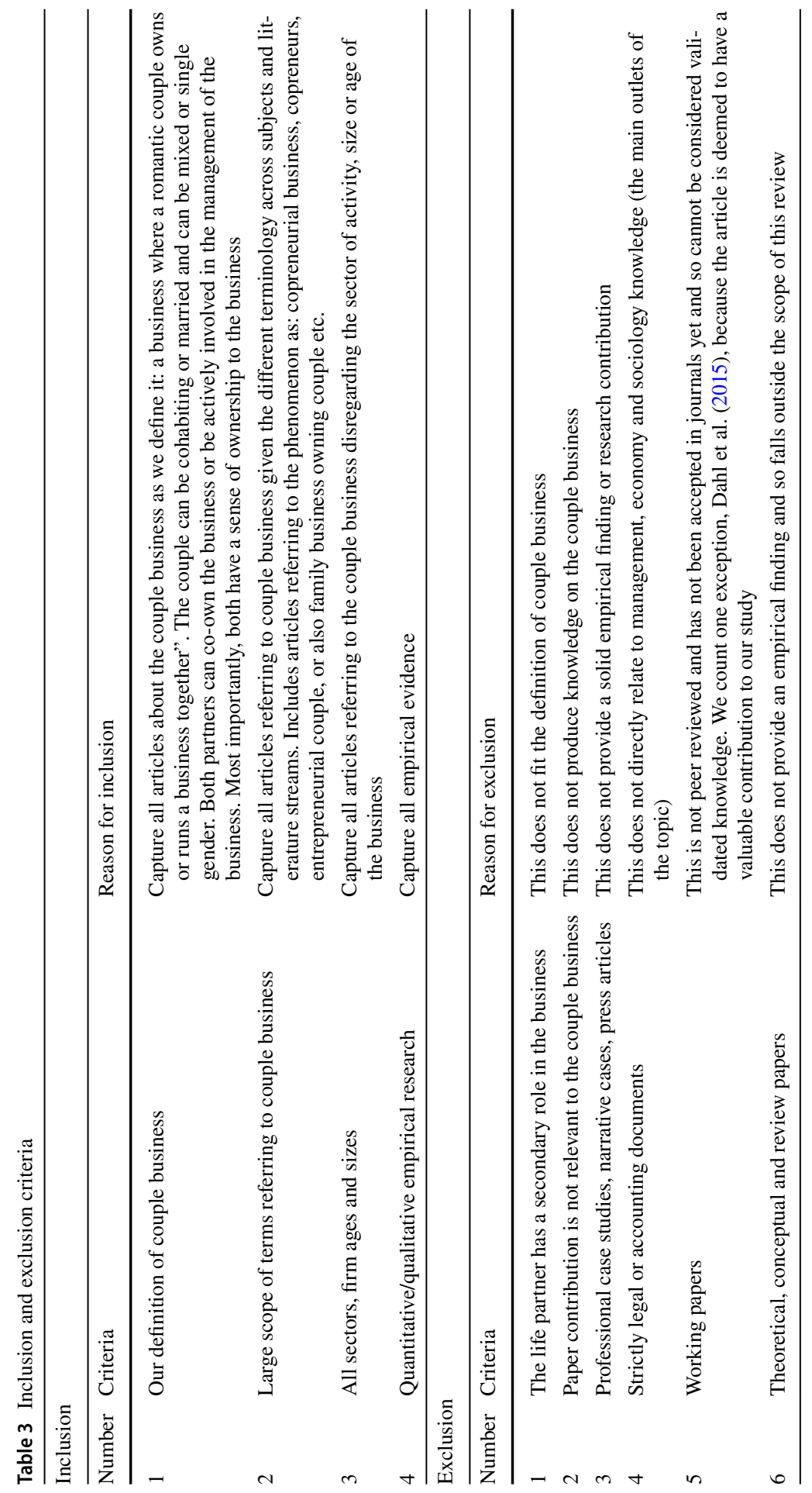


Table 4 Summary of the retrieval of the systematic review articles

Table 5 Review list of articles

\begin{tabular}{lc}
\hline & $\begin{array}{c}\text { Number of } \\
\text { documents }\end{array}$ \\
\hline Systematic search & 4133 \\
ABI ProQuest & 2438 \\
Ebsco (Business Source Premier) & 45 \\
Duplicates & 6526 \\
Total returns & 255 \\
Selected documents: review against the inclusion and & \\
$\quad$ exclusion criteria & 61 \\
Additional documents beyond the systematic search: & 6 \\
Forward inward citations & 4 \\
Agricultural economics journals & 71 \\
Total considered list & \\
\hline
\end{tabular}

\begin{tabular}{|c|c|}
\hline 1 & Amarapurkar and Danes (2005) \\
\hline 2 & Amore et al. (2017) \\
\hline 3 & Andersson et al. (2002) \\
\hline 4 & Baines and Wheelock (1998) \\
\hline 5 & Belenzon et al. (2016) \\
\hline 6 & Bensemann and Hall (2010) \\
\hline 7 & Bird and Zellweger (2018) \\
\hline 8 & Butler and Modaff (2012) \\
\hline 9 & Brannon et al. (2013) \\
\hline 10 & Bratkovic and Antoncic (2009) \\
\hline 11 & Chell and Baines (1998) \\
\hline 12 & Chien (2014) \\
\hline 13 & Cole and Johnson (2007) \\
\hline 14 & Cox et al. (1984) \\
\hline 15 & Craft et al. (2015) \\
\hline 16 & Dahl et al. (2015) \\
\hline 17 & Danes et al. (2005) \\
\hline 18 & Danes and Jang (2013) \\
\hline 19 & Danes and Lee (2004) \\
\hline 20 & Danes et al. (2013) \\
\hline 21 & Danes and Morgan (2004) \\
\hline 22 & Danes (2006) \\
\hline 23 & Danes et al. (2002) \\
\hline 24 & Danes and Olson(2003) \\
\hline 25 & Deacon et al. (2014) \\
\hline 26 & Dyer et al. (2012) \\
\hline 27 & El-Osta et al. (2007) \\
\hline 28 & Epstein (1971) \\
\hline 29 & Farrington et al. (2011a) (structure) \\
\hline 30 & Farrington et al. (2011b) (task) \\
\hline
\end{tabular}


Table 5 (continued)

\begin{tabular}{|c|c|}
\hline 31 & Fitzgerald and Muske (2002) \\
\hline 32 & Fletcher (2010) \\
\hline 33 & Fletcher et al. (2009) \\
\hline 34 & Fletschner (2008) \\
\hline 35 & $\mathrm{Fu}(2020)$ \\
\hline 36 & Hamilton (2006) \\
\hline 37 & Harris et al. (2007) \\
\hline 38 & Hedberg and Danes (2012) \\
\hline 39 & Helmle et al. (2014) \\
\hline 40 & Jang and Danes (2013) \\
\hline 41 & Jurik et al. (2016) \\
\hline 42 & Jurik et al. (2019) \\
\hline 43 & Kirkwood (2009) \\
\hline 44 & Kuschel and Lepeley (2016) \\
\hline 45 & Larsen (2006) \\
\hline 46 & Liang and Dunn (2009) \\
\hline 47 & Machek and Hnilica (2015) \\
\hline 48 & Machek et al. (2015) \\
\hline 49 & Madanoglu et al. (2020) \\
\hline 50 & Marshack (1994) \\
\hline 51 & Matzek et al. (2010) \\
\hline 52 & Mcadam and Marlow (2013) \\
\hline 53 & McDonald et al. (2017) \\
\hline 54 & Millman and Martin (2007) \\
\hline 55 & Mishra et al. (2012) \\
\hline 56 & Muske and Fitzgerald (2006) \\
\hline 57 & Muske et al. (2009) \\
\hline 58 & O'Connor et al. (2006) \\
\hline 59 & Parker (2014) \\
\hline 60 & Parmentier (2011) \\
\hline 61 & Ponthieu and Caudill (1993) \\
\hline 62 & Poza and Messer (2001) \\
\hline 63 & Ruef et al. (2003) \\
\hline 64 & Seymour (2017) \\
\hline 65 & Smith (2000) \\
\hline 66 & Venter et al. (2009) \\
\hline 67 & Venter et al. (2012) \\
\hline 68 & Wicker and Burley (1991) \\
\hline 69 & Wu et al. (2010) \\
\hline 70 & Yang and Danes (2015) \\
\hline 71 & Yang and Aldrich (2014) \\
\hline
\end{tabular}




\section{References}

Ahl HJ (2007) Gender stereotypes. In: Clegg S, Bailey J (eds) International encyclopedia of organization studies. Sage, London, pp 544-547

Aldrich HE, Cliff JE (2003) The pervasive effects of family on entrepreneurship: toward a family embeddedness perspective. J Bus Ventur 18(5):573-596

Amarapurkar SS, Danes SM (2005) Farm business-owning couples: interrelationships among business tensions, relationship conflict quality, and spousal satisfaction. J Fam Econ Issues 26(3):419-441

Amore MD, Miller D, Le Breton-Miller I, Corbetta G (2017) For love and money: marital leadership in family firms. J Corp Finance 46:461-476

Andersson T, Carlsen J, Getz D (2002) Family business goals. Family Bus Rev 15(2):89-106

Andrews MJ, Golan J, Lay J (2014) Inefficiency of male and female labor supply in agricultural households: evidence from Uganda. Am J Agric Econ 97(3):998-1019

Ashforth BE, Kreiner GE, Fugate M (2000) All in a day's work: boundaries and micro role transitions. Acad Manag Rev 25(3):472-491

Astrachan JH, Klein SB, Smyrnios KX (2000) The F-PEC scale of family influence: a proposal for solving the family business definition problem. Family Bus Rev 15(1):45-58

Baines S, Wheelock J (1998) Working for each other: gender, the household and micro-business survival and growth. Int Small Bus J 17(1):16-35

Barnett F, Barnett S (1988) Working together: entrepreneurial couples. Ten Speed Press, Berkeley

Belenzon S, Patacconi A, Zarutskie R (2016) Married to the firm? a large-scale investigation of the social context of ownership. Strateg Manag J 37(13):2611-2630

Bensemann J, Hall CM (2010) Copreneurship in rural tourism: exploring women's experiences. Int J Gender Entrepr 2(3):228-244

Bird M, Zellweger T (2018) Relational embeddedness and firm growth: comparing spousal and sibling entrepreneurs. Organ Sci 29(2):264-283

Blenkinsopp J, Owens G (2010) At the heart of things: the role of the "married" couple in entrepreneurship and family business. Int J Entrepr Behav Res 16(5):357-369

Block J, Goerke L, Millan J, Roman C (2014) Family employees and absenteeism. Econ Lett 123(1):94-99

Block J, Millan J, Roman C, Zhou H (2015) Job satisfaction and wages of family employees. Entrepr Theory Pract 39(2):183-207

Block JH, Fisch CO, Van Praag M (2017) The schumpeterian entrepreneur: a review of the empirical evidence on the antecedents, behaviour and consequences of innovative entrepreneurship. Ind Innov 24(1):61-95

Brannon DL, Wiklund J, Haynie JM (2013) The varying effects of family relationships in entrepreneurial teams. Entrepr Theory Pract 37(1):107-132

Bratkovic T, Antoncic B (2009) Networking of copreneurs and small firm growth: personal sub-networks analysis. Zagreb Int Rev Econ Bus 12(2):33-56

Butler J, Modaff D (2012) "Constructing space and time for work and family: a structuration perspective on bed and breakfasts. Commun Theatre Assoc Minn J 39(1):105-121

Castilla EJ, Benard S (2010) The paradox of meritocracy in organizations. Adm Sci Q 55(4):543-676

Chell E, Baines S (1998) Does gender affect business performance? a study of microbusinesses in business services in the UK. Entrepr Reg Dev 10(2):117-135

Chien SY (2014) Franchisor resources, spousal resources, entrepreneurial orientation, and performance in a couple-owned franchise outlet. Manag Decis 52(5):916-933

Clark SC (2000) Work/family border theory: a new theory of work/family balance. Hum Relat 53(6):747-770

Cole PM, Johnson K (2007) An exploration of successful copreneurial relationships postdivorce. Family Bus Rev 20(3):185-198

Correll SJ, Benard S, Paik I (2007) Getting a job: is there a motherhood penalty? Am J Sociol 112(5):1297-1339

Cox JA, Moore KK, Van Auken PM (1984) Working couples in small business. J Small Bus Manage 22(4):24-30

Craft SM, Seal KL, Jang J, Danes S (2015) Spousal expectations and perceived social support during the creation of a new business venture. J Couple Relatsh Ther 14(2):169-195 
Cruz AD, Hamilton E (2019) Introduction to the virtual special issue: understanding the small family business: past, present and future. Int Small Bus J

Dahl MS, Van Praag M, Thompson P (2015) Entrepreneurial couples. Acad Manag Proc 2015(1):14776

Danes SM (2006) Tensions within family business-owning couples over time. Stress Trauma Crisis 9(3-4):227-246

Danes SM, Jang J (2013) Copreneurial identity development during new venture creation. J Fam Bus Manag 3(1):45-61

Danes SM, Lee YG (2004) Tensions generated by business issues in farm business-owning couples. Fam Relat 53(4):357-366

Danes SM, Morgan EA (2004) Family business-owning couples: an EFT view into their unique conflict culture. Contemp Fam Ther 26(3):241-260

Danes SM, Olson PD (2003) Women's role involvement in family businesses, business tensions, and business success. Fam Bus Rev 16(1):53-68

Danes SM, Rueter MA, Kwon HK, Doherty W (2002) Family FIRO model: an application to family business. Fam Bus Rev 15(1):31-43

Danes SM, Haberman HR, McTavish D (2005) Gendered discourse about family business. Fam Relat 54(1):116-130

Danes SM, Craft SM, Jang J, Lee J (2013) Liability of newness: assessing couple social support when starting a new business venture. J Marital Fam Ther 39(4):515-529

De Bruin A, Lewis K (2004) Toward enriching united career theory: familial entrepreneurship and copreneurship. Career Dev Int 9(7):638-646

de Bruin A, Brush C, Welter F (2006) Introduction to the special issue: towards building cumulative knowledge on women's entrepreneurship. Entrepr Theory Pract 30(5):585-593

Deacon J, Harris J, Worth L (2014) Who leads? Fresh insights into roles and responsibilities in a heterosexual copreneurial business. Int J Gend Entrepr 6(3):317-335

Doherty WJ, Colangelo N, Hovander D (1991) Priority setting in family change and clinical practice: the family FIRO model. Fam Process 30(2):227-240

Dyer JWG, Dyer WJ, Gardner RG (2012) Should my spouse be my partner? preliminary evidence from the panel study of income dynamics. Fam Bus Rev 26(1):68-80

Eagly AH (1997) Sex differences in social behavior: comparing social role theory and evolutionary psychology. Am Psychol 52:1380-1383

El-Osta HS, Mishra AK, Morehart MJ (2007) Determinants of economic well-being among U.S. farm operator households. Agri Econ 36(3):291-304

Epstein CF (1971) Law partners and marital partners: strains and solutions in the dual-career family enterprise. Hum Relat 24(6):549-564

Farrington SM, Venter E, Eybers C, Boshoff C (2011a) Structuring effective copreneurial teams. S Afr J Bus Manag 42(3):1-16

Farrington SM, Venter E, Eybers C, Boshoff C (2011b) Task-based factors influencing the successful functioning of copreneurial businesses in South Africa. S Afr J Econ Manag Sci 14(1):24-46

Fitzgerald M, Muske G (2002) Copreneurs: an exploration and comparison to other family businesses. Fam Bus Rev 15(1):1-16

Fitzpatrick MA, Ritchie LD (1994) Communication schemata within the family: multiple perspectives on family interaction. Hum Commun Res 20(3):275-301

Fletcher D (2010) Life-making or risk taking? co-preneurship and family business start-ups. Int Small Bus J 28(5):452-469

Fletcher D, Helienek E, Zafirova Z (2009) Emergence of a small business sector in Bulgaria. J Enterp Cult 17(3):351-375

Fletschner D (2008) Women's access to credit: does it matter for household efficiency? Am J Agric Econ 90(3):669-683

Fu Y (2020) The impact of married couples on firm innovation: evidence from chinese family firms. Finance Res Lett 30:101220

Gould RV (2002) The origins of status hierarchies: a formal theory and empirical test. Am J Sociol 107(5):1143-1178

Hamilton E (2006) Whose story is it anyway? narrative accounts of the role of women in founding and establishing family businesses. Int Small Bus J 24(3):253-271

Harris C, McIntosh A, Lewis K (2007) The commercial home enterprise: labour with love. Tourism (Zagreb) 55(4):391-402 
Hatak I, Zhou H (2019) Health as human capital in entrepreneurship: individual, extension, and substitution effects on entrepreneurial success. Entrepr Theory Pract. https://doi.org/10.1177/1042258719 867559

Hedberg PR, Danes SM (2012) Explorations of dynamic power processes within copreneurial couples. J Fam Bus Strate 3(4):228-238

Helmle RJ, Botero CI, Seibold RD (2014) Factors that influence perceptions of work-life balance in owners of copreneurial firms. J Fam Bus Manag 4(2):110-132

Henry C, Foss L, Ahl H (2016) Gender and entrepreneurship research: a review of methodological approaches. Int Small Bus J 34(3):217-241

Howorth C, Rose M, Hamilton E (2010) Family firm diversity and development: an introduction. Int Small Bus J 28(5):437-451

Ibrahim AB, Ellis WH (1994) Family business management: concepts and practice. Kendall/Hunt, Dubuque

Jang J, Danes SM (2013) Are we on the same page? copreneurial couple goal congruence and new venture viability. Entrepr Res J 3(4):483-504

Jaouen A, Lasch F (2015) A new typology of micro-firm owner-managers. Int Small Bus J 33(4):397-421

Jurik NC (1998) Getting away and getting by: the experiences of self-employed homeworkers. Work Occup 25(1):7-35

Jurik N, Kř́̌žková A, Pospíšilová M (2016) Czech copreneur orientations to business and family responsibilities: a mixed embeddedness perspective. Int J Gender Entrepr 8(3):307-326

Jurik N, Kř́žzová A, Pospíšilová M, Cavender G (2019) Blending, credit, context: doing business, family and gender in Czech and US copreneurships. Int Small Bus J 37(4):317-342

Kirkwood J (2009) Spousal roles on motivations for entrepreneurship: a qualitative study in New Zealand. J Fam Econ Issues 30(4):372-385

Kreiner GE (2006) Consequences of work-home segmentation or integration: a person-environment fit perspective. J Organ Behav 27(4):485-507

Kuschel K, Lepeley M-T (2016) Copreneurial women in start-ups: growth-oriented or lifestyle? an Aid for technology industry investors. Acad Rev Latinoam Ad 29(2):1-19

Ladd EC, Bowman KH (1998) Attitudes toward economic inequality. American Enterprise Institute Press, Washington, DC

Larsen EA (2006) The impact of occupational sex segregation on family businesses: the case of American harness racing. Gender Work Organ 13(4):359-382

Laspita S, Breugst N, Heblich S, Patzelt H (2012) Intergenerational transmission of entrepreneurial intentions. J Bus Ventur 27(4):414-435

Liang CL, Dunn P (2009) Entrepreneurial couples in new venture creation: reflections on expectations reality and family relationships. Int J Manag Enterp Dev 6(2):165-183

Lynn FB, Podolny JM, Tao L (2009) A sociological (de)construction of the relationship between status and quality. Am J Sociol 115(3):755-804

Machek O, Hnilica J (2015) Copreneurship and its impact on financial characteristics of companies. Ekonomicky Casopis 63(2):152-166

Machek O, Hnilica J, Kolouchová D, Machek M (2015) Are couple-run companies more profitable than professionally managed firms? Int Adv Econ Res 21(3):351-353

Macpherson A, Holt R (2007) Knowledge, learning and small firm growth: a systematic review of the evidence. Res Policy 36(2):172-192

Madanoglu M, Memili E, De Massis A (2020) Home-based family firms, spousal ownership and business exit: a transaction cost perspective. Small Bus Econ 54(4):991-1006

Marshack KJ (1993) Copreneurial couples: a literature review on boundaries and transitions among copreneurs. Fam Bus Rev 6(4):355-369

Marshack KJ (1994) Copreneurs and dual-career couples: are they different? Entrepr Theory Pract 19(1):49-69

Matzek A, Gudmunson C, Danes S (2010) Spousal capital as a resource for couples starting a business. Fam Relat 59(1):60-73

McAdam M, Marlow S (2013) A gendered critique of the copreneurial business partnership: exploring the implications for entrepreneurial emancipation. Int J Entrepr Innov 14(3):151-163

McDonald TM, Marshall MI, Delgado MS (2017) Is working with your spouse good for business? the effect of working with your spouse on profit for rural businesses. J Fam Econ Issues 38(4):477-493

Meyer JW, Rowan B (1977) Institutionalized organizations: formal structure as myth and ceremony. Am J Sociol 83(2):340-363 
Millman C, Martin L (2007) Exploring small copreneurial food companies: female leadership perspectives. Women Manag Rev 22(3):232-239

Mishra AK, El-Osta HS, Ahearn MC (2012) Health care expenditures of self-employed farm households in the U.S. Agric Econ 43(1):75-88

Muske G, Fitzgerald MA (2006) A panel study of copreneurs in business: who enters, continues and exits? Fam Bus Rev 19(3):193-205

Muske G, Fitzgerald MA, Haynes G, Black M, Chin L, MacClure R, Mashburn A (2009) The intermingling of family and business financial resources: understanding the copreneurial couple. J Financ Couns Plan 20(2):27-47

National Federation of Independent Business (NFIB) (2002) Small business poll: families in business. Author, Washington, DC

Nelson GW (1989) Factors of friendship: relevance of significant others to female business owners. Entrepr Theory Pract 13(4):7-18

New Enterprises Information System (SINE) (2002; 2006) Start-ups panel survey. National Institute of Statistics and Economic Studies, France

O'Connor V, Hamouda A, McKeon H, Henry C, Johnston K (2006) Co-entrepreneurial ventures. J Small Bus Enterp Dev 13(4):600-619

Ozcan B (2011) Only the Lonely? the influence of the spouse on the transition to self-employment. Small Bus Econ 37(4):465-492

Parker S (2014) Entrepreneurship among married couples in the United States: a simultaneous probit approach. Labour Econ 15(3):459-481

Parker S (2018) The economics of entrepreneurship. Cambridge University Press, Cambridge

Parmentier MA (2011) When David met Victoria: forging a strong family brand. Fam Bus Rev 24(3):217-232

Pittaway L, Cope J (2007) Entrepreneurship education: a systematic review of the evidence. Int Small Bus J 25(5):479-510

Ponthieu D, Caudill H (1993) Who's the boss? responsibility and decision making in copreneurial ventures. Fam Bus Rev 6(1):3-17

Poza EJ, Messer T (2001) Spousal leadership and continuity in the family firm. Fam Bus Rev 14(1):25-36

Ridgeway CL, Smith-Lovin L (1999) The gender system and interaction. Ann Rev Sociol 25(1):191-216

Rosenblatt PC, de Mik L, Anderson RM, Johnson PA (1985) The family in business: understanding and dealing with the challenges entrepreneurial families face. Jossey-Bass, San Francisco

Ruef M, Aldrich HE, Carter NM (2002) Don't go to strangers: homophily, strong ties, and isolation in the formation of organizational founding teams. American Sociological Association Meeting, Chicago

Ruef M, Aldrich HE, Carter NM (2003) The structure of founding teams: homophily strong ties and isolation among U.S. Entrepreneurs. Am Sociol Rev 68(2):195-222

Salvato C, Aldrich HE (2012) That's interesting! in family business research. Fam Bus Rev 25(2):125-135

Schoar A, Zuo L (2011) Shaped by booms and busts: how the economy impacts CEO careers and managerial styles. In: Unpublished working paper. NBER, Cambridge, MA

Seymour G (2017) "Women's empowerment in agriculture: implications for technical efficiency in rural Bangladesh. Agric Econ 48(4):513-522

Shane SA (2008) The illusions of entrepreneurship: the costly myths that entrepreneurs, investors, and policy makers live by. Yale University Press, New Haven

Shared Business Service (SBS) (2006) SBS Household survey of entrepreneurship 2005. IFF Research, London

Smith CR (2000) Managing work and family in small. Women Manag Rev 15(5/6):283-289

Stafford K, Duncan K, Danes S, Winter M (1999) A research model of sustainable family businesses. Fam Bus Rev 12(3):197-208

Tranfield D, Denyer D, Smart P (2003) Towards a methodology for developing evidence-informed management knowledge by means of systematic review. Br J Manag 14(3):207-222

Unspecified Author (2020) In Europe, and around the world, governments are getting tougher. The Economist March 19

Venter E, Farrington M, Boshoff C (2009) Selected relational-based factors that impact on the successful functioning of copreneurial businesses: a proposed conceptual model. Manag Dyn 18(2):2-21

Venter E, Farrington SM, Boshoff C (2012) Relational-based factors influencing successful copreneurships. Manag Dyn 21(4):14-30

Welter F, Lasch F (2008) Entrepreneurship research in Europe: taking stock and looking forward. Entrepr Theory Pract 32(2):241-248 
Westhead P, Howorth C, Cowling M (2002) Ownership and management issues in first generation and multi-generation family firms. Entrepr Region Dev 14(3):247-269

Wicker AW, Burley KA (1991) Close coupling in work-family relationships: making and implementing decisions in a new family business and at home. Hum Relat 44(1):77-92

Winch RF (1970) Permanence and change in the history of the american family and some speculations as to its future. J Marriage Fam 32(1):6-15

Wooldridge A (2020) Coronavirus etiquette: greeting in the age of social distance. The Economist: March 18

Wu M, Chang CC, Zhuang WL (2010) Relationships of work-family conflict with business and marriage outcomes in taiwanese copreneurial women. Int J Hum Resour Manag 21(5):742-753

Yang T, Aldrich HE (2014) Who's the boss? explaining gender inequality in entrepreneurial teams. Am Sociol Rev 79(2):303-327

Yang Y, Danes SM (2015) Resiliency and resilience process of entrepreneurs in new venture creation. Entrepr Res J 5(1):1-30

Yin RK (1994) Case study research. Sage, Thousand Oaks

Publisher's Note Springer Nature remains neutral with regard to jurisdictional claims in published maps and institutional affiliations. 